\title{
Greatly promoted oxygen reduction reaction activity of solid catalysts by regulating the stability of superoxide in metal- $\mathrm{O}_{2}$ batteries
}

\author{
Hua Wang ${ }^{1 \dagger}$, Liangliang $\mathrm{Liu}^{1 \dagger}$, Xiao Liu ${ }^{1}, \mathrm{Yu} \mathrm{Jia}^{1}$, Peng Zhang ${ }^{2,3^{*}}$ and Yong $\mathrm{Zhao}^{{ }^{*}}$
}

ABSTRACT Oxygen reduction reactions (ORRs) with one- or two-electron-transfer pathways are the essential process for aprotic metal-oxygen batteries, in which the stability of superoxide intermediates/products $\left(\mathrm{O}_{2}^{-}, \mathrm{LiO}_{2}, \mathrm{NaO}_{2}\right.$, etc. $)$ mainly dominates the ORR activity/stability and battery performance. However, little success in regulating the stability of the superoxides has been achieved due to their highly reactive characteristics. Herein, we identified and modulated the stability of superoxides by introducing anthraquinone derivatives as cocatalysts which functioned as superoxide trapper adsorbing the superoxides generated via surface-mediated ORR and then transferring them from the solid catalyst surface into electrolyte. Among the studied trappers, 1,4-difluoroanthraquinone (DFAQ) with electron-withdrawing groups showed the highest adsorption towards superoxides and could efficiently stabilize $\mathrm{LiO}_{2}$ in electrolyte, which greatly promoted the surface-mediated ORR rate and stability. This highlighted the magnitude of adsorption between the trapper and $\mathrm{LiO}_{2}$ on the ORR activity/ stability. Using an aprotic $\mathrm{Li}-\mathrm{O}_{2}$ battery as a model metal- $\mathrm{O}_{2}$ battery, the overall performance of the cell with DFAQ was substantially improved in terms of cell capacity, rate capability and cyclic stability. These results represent a significant advance in the understanding of ORR mechanisms and promoting the performance of metal- $\mathrm{O}_{2}$ batteries.

Keywords: oxygen reduction reaction, adsorption energy, superoxide, lithium oxygen battery

\section{INTRODUCTION}

Oxygen reduction reactions (ORRs) with one- $\left(1 \mathrm{e}^{-}\right)$or two-electron-transfer $\left(2 \mathrm{e}^{-}\right)$pathways $\left(\mathrm{M}^{+}+\mathrm{O}_{2}+\mathrm{e}^{-} \rightarrow \mathrm{MO}_{2}\right.$; $\mathrm{MO}_{2}+\mathrm{M}^{+}+\mathrm{e}^{-} \rightarrow \mathrm{M}_{2} \mathrm{O}_{2}$ ) are the essential processes in aprotic metal-oxygen $\left(\mathrm{M}-\mathrm{O}_{2}\right)$ batteries, which have been considered as one of the promising large-capacity batteries due to their high theoretical energy density [1-5]. The superoxide intermediates/products $\left(\mathrm{MO}_{2}\right.$, such as $\mathrm{LiO}_{2}$ and $\mathrm{NaO}_{2}$ ) are a kind of highly reactive agents, and their stability plays a dominant role in controlling the ORR activity/stability and overall performance of $\mathrm{M}-\mathrm{O}_{2}$ batteries [4-7]. In the last decade, numerous solid catalysts have been designed to improve ORR by optimizing the bond strength between the surface active sites and $\mathrm{MO}_{2}$ [8-11]. However, ORR activity initiated from the active site is quickly lost due to the deposition of low conductive and film-like $\mathrm{MO}_{2}$ and $\mathrm{M}_{2} \mathrm{O}_{2}$ products on the cathode, and this further results in termination of the surface-mediated ORR process at the solid catalysts [12$15]$, and thereby induces the low capacity and poor rate capability of the aprotic $\mathrm{M}-\mathrm{O}_{2}$ batteries [14,16,17]. Also, some strong oxidizing $\mathrm{MO}_{2}$ intermediates, such as $\mathrm{LiO}_{2}$ and $\mathrm{NaO}_{2}$ can react with the electrolyte component via a nucleophilic reaction, leading to low ORR stability at the electrode surface and low cyclic stability of $\mathrm{M}-\mathrm{O}_{2}$ batteries [18-20]. Therefore, inhibition or stabilization of $\mathrm{MO}_{2}$ from surface-mediated ORR is a key to improving the activity and stability of $1 \mathrm{e}^{-}$and $2 \mathrm{e}^{-} \mathrm{ORR}$, as well as the overall performance of $\mathrm{M}-\mathrm{O}_{2}$ batteries.

Promoting solution-mediated $1 \mathrm{e}^{-}$and $2 \mathrm{e}^{-} \mathrm{ORR}$ with the aid of redox mediators ( $\mathrm{RMs})\left(\mathrm{RM}^{-}+\mathrm{M}^{+}+\mathrm{O}_{2} \rightarrow \mathrm{RM}+\mathrm{MO}_{2}\right.$; $\left.\mathrm{RM}^{-}+\mathrm{M}^{+}+\mathrm{O}_{2} \rightarrow \mathrm{RM}+\mathrm{MO}_{2} \rightarrow \mathrm{RM}+\mathrm{M}_{2} \mathrm{O}_{2}+\mathrm{O}_{2}\right) \quad[17,21-24]$,

\footnotetext{
${ }^{1}$ Key Lab for Special Functional Materials of Ministry of Education; National \& Local Joint Engineering Research Center for High-efficiency Display and Lighting Technology; School of Materials Science and Engineering; Collaborative Innovation Center of Nano Functional Materials and Applications; Henan University, Kaifeng 475004, China

${ }^{2}$ Department of Materials Science \& Engineering, Shenzhen, Key Laboratory of Solid State Batteries Shenzhen, Guangdong Provincial Key Laboratory of Energy Materials for Electric Power, Southern University of Science and Technology, Shenzhen 518055, China

${ }^{3}$ College of Chemistry and Molecular Sciences, Hubei Key Laboratory of Electrochemical Power Sources, Wuhan University, Wuhan 430072, China

${ }^{\dagger}$ These authors contributed equally to this work.

* Corresponding authors (emails: zp1211mj@163.com (Zhang P); zhaoyong@henu.edu.cn (Zhao Y))
} 
such as viologen [21], 2,5-di-tert-butyl-1,4-benzoquinone (DBBQ) [22] and coenzyme Q10 [23], is considered to be an effective strategy to inhibit the formation of adsorbed $\mathrm{MO}_{2}$ from surface-mediated ORR, and thus postpone the deposition of $\mathrm{MO}_{2}$ or $\mathrm{M}_{2} \mathrm{O}_{2}$ film on the cathode surface. However, this RM-assisted solution-mediated ORR is an indirect electron transfer process, and its reaction rate is limited by the diffusion rate of RM molecules [25-27], much lower than that of surface-mediated ORR involving a direct electron transfer pathway. Simultaneously, adsorbed $\mathrm{MO}_{2}$ species are inevitably produced on the cathode surface, especially the catalytic cathode which has abundant active sites, and they cannot be stabilized by the reaction of $\mathrm{RM}^{-}$and $\mathrm{MO}_{2}{ }^{*}: \mathrm{RM}^{-}+\mathrm{MO}_{2}{ }^{*}+\mathrm{Li}^{+} \rightarrow \mathrm{RM}+\mathrm{M}_{2} \mathrm{O}_{2}$ $[28,29]$. Hence, the stabilization of adsorbed $\mathrm{MO}_{2}$ from surface-mediated ORR remains a significant challenge for achieving high-performance $\mathrm{M}-\mathrm{O}_{2}$ batteries.

In this study, modulation of $\mathrm{MO}_{2}$ stability was achieved by introducing anthraquinone $(\mathrm{AQ})$ derivatives to trap and stabilize the $\mathrm{MO}_{2}$ generated from the solid catalyst surface and then transfer them into the electrolyte. Based on this cooperative catalysis between the solid catalyst and AQ derivatives, the ORR activity and stability of the solid catalysts were significantly enhanced. Difluoroanthraquinone (DFAQ), a trapper compound with electron withdrawing groups (two $-\mathrm{F}$ ), showed the highest adsorption energy (AE) toward $\mathrm{MO}_{2}$ and thus maximum ORR rate and stability (Fig. 1). The current densities at the defined potentials were over 10 times higher compared with the blank carbon catalysts. Taking the aprotic $\mathrm{Li}-\mathrm{O}_{2}$ battery as a model $\mathrm{M}-\mathrm{O}_{2}$ battery, DFAQ significantly boosted its discharge capacity $\left(4 \rightarrow 17 \mathrm{~mA} \mathrm{~h} \mathrm{~cm}^{-2}\right)$, cycle stability ( $25 \rightarrow 171$ cycles) and rate capability ( $2-3$ times).

\section{EXPERIMENTAL SECTION}

\section{Preparation of CP@CNTs cathode}

Carbon paper (CP) was cut into circular sheet with a diameter of $12 \mathrm{~mm}$, and then soaked in acetone for $20 \mathrm{~min}$ to remove oil stains. After being dried at $30^{\circ} \mathrm{C}$, it was treated by oxygen plasma for $5 \mathrm{~min}$, and then immersed in $10 \mathrm{~mL}$ ethanol containing $400 \mathrm{mg} \mathrm{NiCl} \cdot 6 \mathrm{H}_{2} \mathrm{O}$ for $12 \mathrm{~h}$. Self-supporting CP@carbon nanotube (CP@ $\mathrm{CNT}$ ) material was prepared with $\mathrm{CP}$ as substrate for the growth of CNTs, ethanol as carbon source and $\mathrm{Ar}-\mathrm{H}_{2}$ mixture as carrier gas at $700^{\circ} \mathrm{C}$ for $2 \mathrm{~h}$.

\section{Preparation of PSS-Li/GO-Li/GF separator}

The preparation method of the separator refers to our previous report [30]. Briefly, lithiated graphene oxide

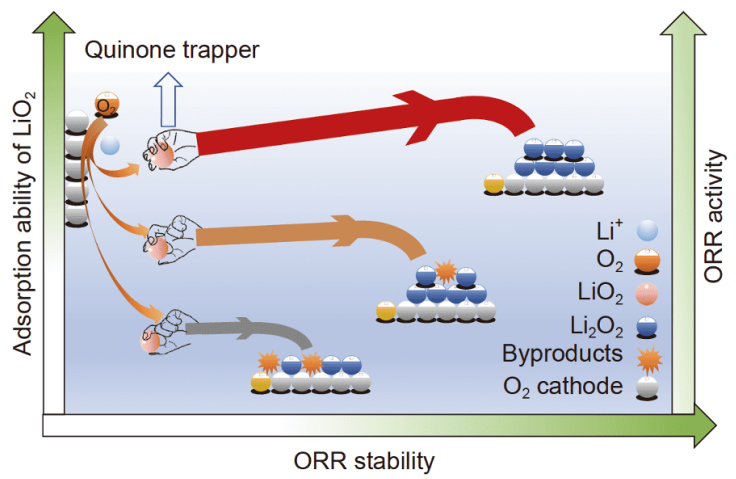

Figure 1 Schematic diagram of the role of Quinone-trapper in improving the oxygen reduction reaction (ORR) activity and stability. If the interaction between trapper and $\mathrm{LiO}_{2}$ (simulated with different gesture) is stronger, the surface formed $\mathrm{LiO}_{2}$ can be removed faster, and the surface-active sites can be regenerated more quickly. This ensures the high reaction rate of surface-mediated ORR. Simultaneously, the high interaction between Quinone-trapper and $\mathrm{LiO}_{2}$ indicates the high stability of Quinone- $\mathrm{LiO}_{2}$ complex and thus reduces the byproduct generated from $\mathrm{LiO}_{2}$, ensuring the high stability of surface-mediated ORR.

(GO-Li), lithium polystyrene sulfonate (PSS-Li) and silica were mixed in tetraethylene glycol dimethyl ether (TEGDME) solvent with a mass ratio of 4:10:15, and then the mixture was dispersed uniformly by ultrasound for $2 \mathrm{~h}$. The above suspension was filtered into the glass fiber (GF) separator to form the polymer-based separator which was further filtered with the dropped $60 \mathrm{~mL}$ deionized water to obtain PSS-Li/GO-Li/GF separator. Finally, the separator was vacuum-dried at $60^{\circ} \mathrm{C}$ for $12 \mathrm{~h}$.

\section{Electrochemical cyclic voltammetry (CV)}

$\mathrm{CV}$ was carried out on an Autolab electrochemical workstation (Metrohm) in a three-electrode system at $25^{\circ} \mathrm{C}$. Carbon plates $\left(1 \mathrm{~cm}^{2}\right)$ were used as the working electrodes, and lithium metal foils were used as the reference and counter electrodes, respectively.

\section{Li- $\mathrm{O}_{2}$ battery assembly}

$\mathrm{Li}-\mathrm{O}_{2}$ batteries were assembled in glove boxes filled with Ar gas. CP@CNT was used as the cathode, and TEGDME dissolving $1 \mathrm{~mol} \mathrm{~L}^{-1}$ lithium bis (trifluoromethanesulphonyl) imide (LiTFSI) was used as the electrolyte. Li foil and cathode were separated by the PSS-Li/GO-Li/GF separator. The cell capacities were calculated by the geometric area of cathode. All batteries were tested at $25^{\circ} \mathrm{C}$.

\section{Physical characterization}

To characterize the discharged electrodes, all batteries were dissembled in an Ar-filled glove box. The electrodes 
were washed by DME for three times to remove the electrolyte. The electrodes were then dried in a vacuum chamber for further characterization. X-ray diffraction (XRD) tests were carried out on a powder XRD system using $\mathrm{Cu} \mathrm{Ka}$ radiation (D8-ADVANCE, Bruker, Gemany). Field emission scanning electron microscopy (FESEM, Nova NanoSEM 450, FEI, USA) was used to check the morphology of electrodes. Raman spectra were measured by Renishoin Via spectrometer $(10 \mathrm{~mW}$, $785 \mathrm{~nm}$ ). For FTIR spectra test (VERTEX 70, Brook, Gemany), the dried electrodes were scraped and pressed into a slice by mixing with $\mathrm{KBr}$ in the glove box. Proton nuclear magnetic resonance $\left({ }^{1} \mathrm{H}\right.$ NMR) spectra were obtained on Bruker ADVANCE. DMSO-d (dimethyl sulfoxide, DMSO) was used as the solvent and its chemical shift of ${ }^{1} \mathrm{H}$ NMR was $2.5 \mathrm{ppm}$. The quinone concentration was around $10 \mathrm{mmol} \mathrm{L}^{-1}$ and the amount of $\mathrm{KO}_{2}$ was excess. For the test of quinone $+\mathrm{KO}_{2}+\mathrm{Li}^{+}$sample, $0.1 \mathrm{~mol} \mathrm{~L}^{-1}$ LiTFSI was added into the NMR tube containing quinone $+\mathrm{KO}_{2}$. After that, the tube was quickly transformed into the NMR device.

\section{Theoretical calculation}

In order to study the adsorption energy of $\mathrm{LiO}_{2}$ on different quinone molecules, the spin polarization densityfunctional-theory (DFT) calculations based on planewave were carried out using the Vienna $A b$ initio simulation software package. For confirming the exchangecorrelation energy, we used the generalized gradient approximation function of Perdew-Burke-Ernzerhof (PBE). The electron-ion interaction was treated in the enhanced wave frame of the projector. The convergence criteria for electron and ion optimization were $10^{-5} \mathrm{eV}$ and $0.01 \mathrm{eV} \AA^{-1}$, respectively, and the energy cut-off of plane wave basis set was $500 \mathrm{eV}$. The system energy was calculated at the $\Gamma$ point. The interaction between adjacent atoms was eliminated by using a $30 \AA \times 30 \AA \times 30 \AA$ box. In order to determine the local charge of atoms in the system, Bader charge analysis was used. Previous studies have shown that Bader charge analysis can correctly describe the charge states of atoms.

\section{RESULTS AND DISCUSSION}

\section{Theoretical and experimental results for the bound state of the trapper- $\mathrm{LiO}_{2}$ complex}

The effect of the molecular structures of $\mathrm{AQ}$ derivatives on their binding strength toward $\mathrm{LiO}_{2}$ was initially studied using DFT calculation. As shown in Fig. 2, the electron-donating moiety of 2-tert-butylanthraquinone
(TBAQ) increased the electron density of $\mathrm{C}=\mathrm{O}$, and the AE toward $\mathrm{LiO}_{2}$ decreased from -1.01 to $-0.98 \mathrm{eV}$ compared with that of AQ (Fig. 2a and b) [29]. In contrast, the electron density of $\mathrm{C}=\mathrm{O}$ in DFAQ decreased due to the electron-withdrawing effect of the fluorine group. Thus, DFAQ showed the highest $\mathrm{LiO}_{2} \mathrm{AE}$ of $-1.06 \mathrm{eV}$ among the three trappers (Fig. 2c).

To confirm the existence of trapper- $\mathrm{LiO}_{2}$ species in the electrolyte, ${ }^{1} \mathrm{H}$ NMR spectroscopy was used to measure the ${ }^{1} \mathrm{H}$ chemical shifts $(\delta)$ of TBAQ and DFAQ in the presence of $\mathrm{Li}^{+}, \mathrm{KO}_{2}, \mathrm{Li}^{+}$and $\mathrm{KO}_{2}$, respectively (Fig. $2 \mathrm{~d}$ and $\mathrm{f}$. A theoretical calculation of electron densities at the different carbon atoms of TBAQ and DFAQ was also obtained to evaluate $\delta$ (Fig. 2e and g). Compared with a previous report [29], the $\delta$ of DFAQ did not change when $\mathrm{Li}^{+}$was added (red and blue lines, Fig. 2d). The ${ }^{1} \mathrm{H}$ NMR gave three peaks at $\delta(\mathrm{ppm}) 8.15,7.92,7.87$, which were assigned to $\mathrm{C} 1 / \mathrm{C} 6, \mathrm{C} 2 / \mathrm{C} 5, \mathrm{C} 3 / \mathrm{C} 4$, respectively. These were confirmed by theoretical calculation and shown in Fig. 2e (black square). After the addition of $\mathrm{KO}_{2}$ alone, DFAQ was reduced to DFAQ ${ }^{-}$by $\mathrm{KO}_{2}$ and six signals appeared at $\delta(\mathrm{ppm}) 6.65,7.12,7.65,7.75,8.00$ and 8.15 (pink line, Fig. 2d). They were confirmed to be C4, C3, C5, C2, C6 and C1, respectively (pink dot, Fig. 2e). After the addition of $\mathrm{Li}^{+}$and $\mathrm{KO}_{2}$, the number of peaks was unchanged but the corresponding $\delta$ moved towards the high field region compared with that of $\mathrm{DFAQ}^{-}$, indicating a decrease of electron density at carbon atoms. The decrease in chemical shift observed for the change from DFAQ ${ }^{-}$to DFAQ- $\mathrm{LiO}_{2}$ was due to the introduction of $\mathrm{Li}^{+}$into situation of DFAQ and $\mathrm{KO}_{2}$. The formation of DFAQ- $\mathrm{LiO}_{2}$ complex was further confirmed by theoretical calculation (blue triangle, Fig. 2e). Similarly, TBAQ was reduced to $\mathrm{TBAQ}^{-}$when $\mathrm{KO}_{2}$ was added. After adding both $\mathrm{Li}^{+}$and $\mathrm{KO}_{2}$, the $\delta$ of ${ }^{1} \mathrm{H}$ on $\mathrm{C} 1-\mathrm{C} 6$ were also increased, indicating the transformation of $\mathrm{TBAQ}^{-}$to TBAQ- $\mathrm{LiO}_{2}$ (Fig. $2 \mathrm{f}$ and g). As shown in Fig. 2g, the electron density of $\mathrm{C}$ atoms in the case of TBAQ with $\mathrm{Li}^{+}$ and $\mathrm{KO}_{2}$ was different from that of TBAQ with $\mathrm{KO}_{2}$, consistent with the effect of $\mathrm{LiO}_{2}$ on $\delta$ of TBAQ. Thus, the stable existence of TBAQ- $\mathrm{LiO}_{2}$ species was demonstrated experimentally and theoretically.

Based on the above evidence, the quinone trapper could capture the $\mathrm{LiO}_{2}$ from solid catalyst surface and transfer it into electrolyte, postponing the passivation of ORR activity sites. Consequently, the bound state of $\mathrm{LiO}_{2}$ on the solid catalyst was also a key parameter requiring investigation. As shown in Fig. 3, taking widely used carbon as a mode material, the AEs of $\mathrm{LiO}_{2}$ on pristine graphene layer (Fig. 3a), single vacancy site (Fig. 3b) and hydroxyl 
$\mathbf{a}$

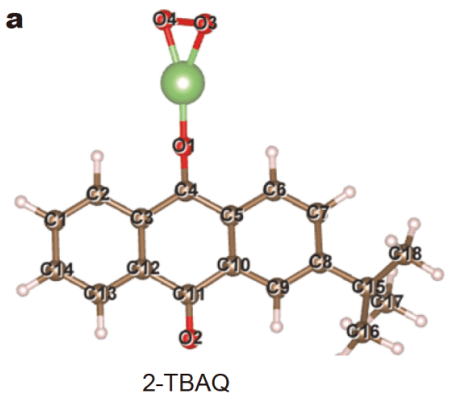

$\mathrm{AE}$ of $\mathrm{LiO}_{2}:-0.98 \mathrm{eV}$ b

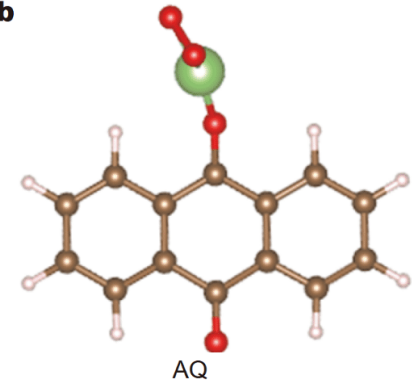

$\mathrm{AE}$ of $\mathrm{LiO}_{2}:-1.01 \mathrm{eV}$

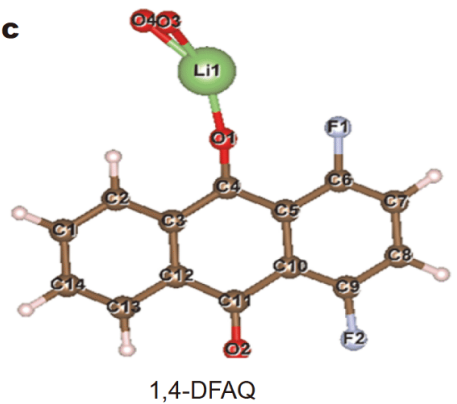

$\mathrm{AE}$ of $\mathrm{LiO}_{2}:-1.06 \mathrm{eV}$
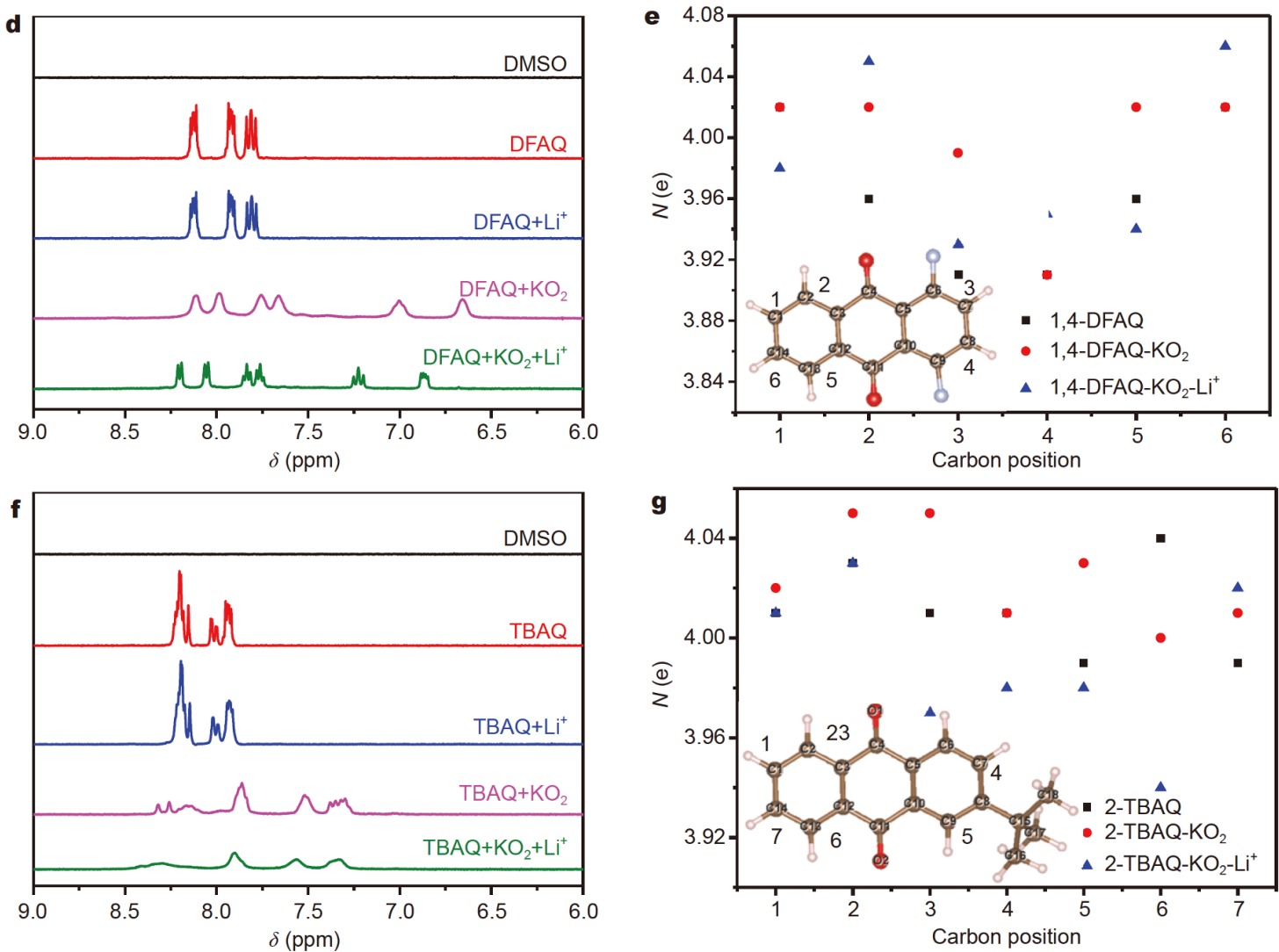

Figure 2 Simulated situation of $\mathrm{LiO}_{2}$ adsorbed on TBAQ (a), AQ (b) and DFAQ (c). Adsorption energy is also provided for all the molecules. Red spheres represent "O", green ones represent "Li", pink ones represent " $\mathrm{H}$ ", and brown ones represent "C". (d) ${ }^{1} \mathrm{H}$ NMR spectra of DFAQ after adding $\mathrm{Li}^{+}, \mathrm{KO}_{2}$, and both $\mathrm{Li}^{+}$and $\mathrm{KO}_{2}$. (e) Number of electrons at different carbon positions of DFAQ corresponding to (d). (f) ${ }^{1} \mathrm{H}$ NMR spectra of TBAQ after adding $\mathrm{Li}^{+}, \mathrm{KO}_{2}$, and both $\mathrm{Li}^{+}$and $\mathrm{KO}_{2}$. (g) Number of electrons at different carbon positions of TBAQ corresponding to (f). The carbon sites are marked with Arabic numerals in illustrations of DFAQ and TBAQ molecule structure, which are presented as the insets in (e) and (g), respectively.

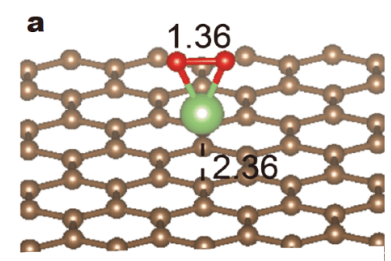

AE of $\mathrm{LiO}_{2}:-0.08 \mathrm{eV}$

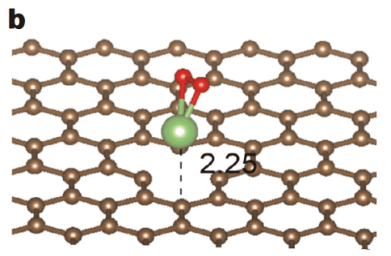

$\mathrm{AE}$ of $\mathrm{LiO}_{2}:-1.27 \mathrm{eV}$

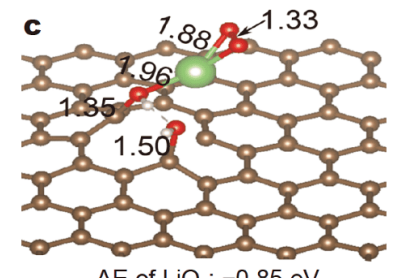

$\mathrm{AE}$ of $\mathrm{LiO}_{2}:-0.85 \mathrm{eV}$

Figure 3 The adsorption energies of $\mathrm{LiO}_{2}$ on pristine carbon surface (a), single vacancy site (b) and hydroxyl modified single vacancy (c). The unit of the bound length is $\AA$. 
modified single vacancy (Fig. 3c) were calculated and these values were $-0.08,-1.27$, and $-0.85 \mathrm{eV}$, respectively. The latter two results were close to the values of the binding energies of quinones on $\mathrm{LiO}_{2}$, which theoretically proved the feasibility of introducing the quinone trapper to prompt the surface-mediated ORR activity.

In addition to the thermodynamic binding energy results, the kinetic diffusion ability of these AQ-derivatives was another important parameter to enhance the surfacemediated ORR activity. The diffusion coefficient (DC) of $\mathrm{AQ}$ derivatives was then calculated by analyzing the $\mathrm{CV}$ curves with different scan rates. DFAQ and AQ both gave the comparable DCs $\left(1.53 \times 10^{-6}\right.$ vs. $\left.1.54 \times 10^{-6} \mathrm{~cm}^{2} \mathrm{~s}^{-1}\right)$, which were higher than those of TBAQ $\left(1.07 \times 10^{-6} \mathrm{~cm}^{2} \mathrm{~s}^{-1}\right)$ and DBBQ $\left(6.28 \times 10^{-7} \mathrm{~cm}^{2} \mathrm{~s}^{-1}\right)$ (Fig. S1). The different DC values can be ascribed to the steric hindrance of functional groups, because one and two tert-butyl groups were present in TBAQ and DBBQ molecules, respectively. The above results indicated that DFAQ and AQ had high capabilities of transferring $\mathrm{LiO}_{2}$ from the electrode to electrolyte. Additionally, the stability of these molecules was also investigated to confirm whether they were suitable to be used in $\mathrm{Li}-\mathrm{O}_{2}$ batteries. Fig. S2 shows that the CV curves of $A Q$ and DFAQ were overlapped perfectly over 200 cycles. In contrast, a small oxidation peak appeared in the profiles of DBBQ and TBAQ in the potential range of $3-4 \mathrm{~V} v s$. $\mathrm{Li}^{+} / \mathrm{Li}$, which may be related to the oxidation of tert-butyl groups. We further confirmed the chemical stability of AQ derivatives and DBBQ after storage in $\mathrm{KO}_{2}$-saturated TEGDME solvent. This confirmed the high chemical stability of AQ and TBAQ toward $\mathrm{O}_{2}^{-}$species (Fig. S3).

\section{Influence of trapper- $\mathrm{LiO}_{2}$ complex on surface-mediated ORR activity}

Based on above results, the relationship between the $\mathrm{AE}$ of trapper- $\mathrm{LiO}_{2}$ and the surface-mediated ORR activity was then investigated. As shown in Fig. $4 \mathrm{a}-\mathrm{c}$, the onset ORR potentials at the graphite carbon electrode were higher than the redox potentials of the three AQ derivatives (black line $v s$. red line), suggesting that the first step of ORR was $\mathrm{O}_{2}$ accepting an electron from the electrode surface and combining with $\mathrm{Li}^{+}$to form $\mathrm{LiO}_{2}$ [31]. In addition, all the $A Q$ derivatives exhibited the new cathodic peaks $(2.21 \mathrm{~V}$ for TBAQ, $2.40 \mathrm{~V}$ for AQ and $2.46 \mathrm{~V}$ for $\mathrm{DFAQ}$ ) and the new cathodic peaks of the $\mathrm{CV}$ curves under $\mathrm{O}_{2}$ could be assigned to the trapper- $\mathrm{LiO}_{2}$ complex (blue line). These greatly enhanced ORR currents can be attributed to the improved surface-mediated ORR rate with the aid of quinone trappers. It should be
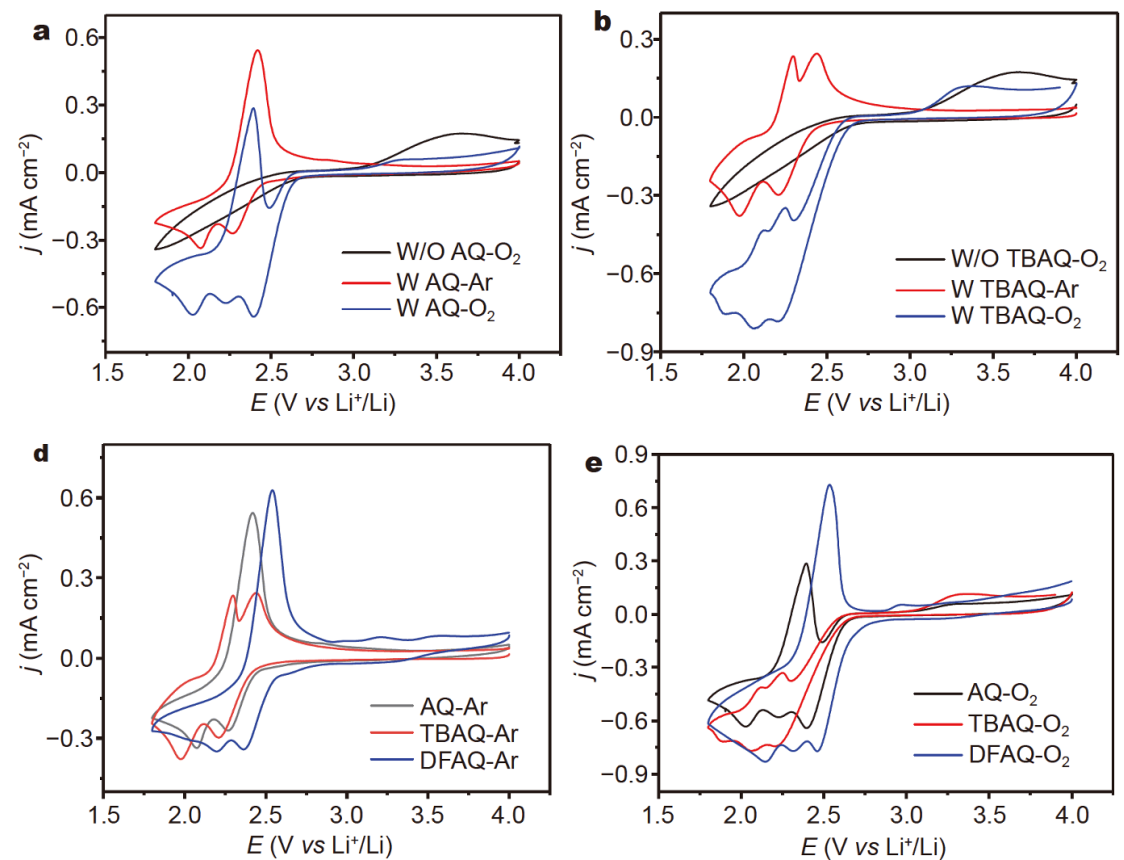

Figure $44 \mathrm{CV}$ curves of $\mathrm{AQ}$ (a), TBAQ (b), DFAQ (c) under $\mathrm{Ar}$ (red), $\mathrm{O}_{2}$ (blue) and the CV profiles of direct $\mathrm{O}_{2}$ reduction (black). (d) Comparison of CV curves of AQ (black), TBAQ (red) and DFAQ (blue) under Ar. (e) Comparison of CV curves of these molecules under $\mathrm{O}_{2}$. (f) The relationship between ORR activity and adsorption energy of the trapper to $\mathrm{LiO}_{2}$. The electrolyte is $1 \mathrm{~mol} \mathrm{~L}^{-1} \mathrm{LiTFSI} / \mathrm{TEGDME}$; a piece of CP is used as the working electrode; metallic lithium foils are used as the counter and the reference electrodes; the concentration of all additives is $10 \mathrm{mmol} \mathrm{L}^{-1}$. The applied scan rate is $10 \mathrm{mV} \mathrm{s}$. 
noted that the peak current densities of TBAQ- and DFAQ-assisted ORR were higher than that obtained with AQ $\left(\sim 0.8 v s . \sim 0.6 \mathrm{~mA} \mathrm{~cm}^{-2}\right)$. This may be due to the limited solubility of AQ molecule in LiTFSI/TEGDME electrolyte $\left(<10 \mathrm{mmol} \mathrm{L}^{-1}\right.$, the solubility of TBAQ and DFAQ is much higher than $10 \mathrm{mmol} \mathrm{L}^{-1}$ ). Owing to the electron-donating tert-butyl group of TBAQ and electron-withdrawing fluoro group of DFAQ, their redox potentials locate on the left and right of the original AQ, respectively (Fig. $4 \mathrm{~d}$ ). This trend is followed by the CV profiles under $\mathrm{O}_{2}$ atmosphere (Fig. 4e), indicating that the surface-mediated ORR potentials are related to the stability of trapper- $\mathrm{LiO}_{2}$ complex. At a current density of $-0.3 \mathrm{~mA} \mathrm{~cm}{ }^{-2}$, the corresponding ORR potentials with the addition of TBAQ, AQ and DFAQ were 2.45, 2.52 and $2.60 \mathrm{~V} v$ s. $\mathrm{Li} / \mathrm{Li}^{+}$, respectively. At a constant ORR potential of $2.5 \mathrm{~V} v s . \mathrm{Li} / \mathrm{Li}^{+}$, the current densities with the addition of TBAQ, AQ and DFAQ were $-0.22,-0.39$ and $-0.64 \mathrm{~mA} \mathrm{~cm}^{-2}$, respectively (Fig. 4f). These results showed that AQ derivatives with different electron-donating/electron-withdrawing groups could regulate their redox potentials and the stability of trapper- $\mathrm{LiO}_{2}$ species in a role that was a key to accelerate the surface-mediated ORR. The same situation was also found in polar DMSO solvent (Fig. S4), although higher redox potentials were obtained for AQ derivatives compared with those in TEGDME. This phenomenon could be attributed to the different polarities of the two solvents, and a similar result was observed in previous reports [32,33]. In this study, DBBQ, one of the best soluble ORR catalysts reported so far, was also chosen as the reference. The comparison of ORR current densities of these AQ derivatives and DBBQ in Fig. S5 showed that DFAQ- and TBAQ-assisted ORR currents were as high as the DBBQ-assisted value at the flat carbon electrode.

\section{The mechanism of surface-mediated ORR in the presence and absence of trapper}

In the absence of $\mathrm{AQ}$ derivatives, the $\mathrm{LiO}_{2}$ produced via surface-mediated ORR are prone to self-disproportionation, resulting in the generation of film-like $\mathrm{Li}_{2} \mathrm{O}_{2}$ products $\left(\mathrm{Li}^{+}+\mathrm{O}_{2}+\mathrm{e}^{-} \rightarrow \mathrm{LiO}_{2} \rightarrow \mathrm{Li}_{2} \mathrm{O}_{2}+\mathrm{O}_{2}\right)$ and deactivation of catalytic sites on the cathode surface $[34,35]$. In the presence of AQ derivatives, $\mathrm{LiO}_{2}$ can be captured, stabilized and transferred from the cathode surface through the formation of stable complex with these additives. In this way, the surface $\mathrm{LiO}_{2}$ disproportionation reaction was inhibited, and solution-growth of $\mathrm{Li}_{2} \mathrm{O}_{2}$ was achieved. As a result, the catalytic active sites on the cathode surface can be regenerated, thus enhancing the catalytic ORR current densities. Although the bond strength of DFAQ$\mathrm{LiO}_{2}(1.06 \mathrm{eV})$ was only 0.05 and $0.08 \mathrm{eV}$ higher than those of AQ- $\mathrm{LiO}_{2}(1.01 \mathrm{eV})$ and TBAQ- $\mathrm{LiO}_{2}(0.98 \mathrm{eV})$, respectively, the surface-mediated ORR activities were greatly promoted (Fig. 4f). For example, at a potential of $2.5 \mathrm{~V} v s . \mathrm{Li} / \mathrm{Li}^{+}$, the current density with the addition of DFAQ $\left(-0.64 \mathrm{~mA} \mathrm{~cm}^{-2}\right)$ was about 2.9 and 1.6 times those of TBAQ and AQ, respectively. It indicates that a small increase of bond strength between the trapper and $\mathrm{LiO}_{2}$ can greatly accelerate the capture and transfer of $\mathrm{LiO}_{2}$ from the electrode surface. Thus, DFAQ can rapidly regenerate the catalytic active sites and promote the surface-mediated ORR activities.

\section{The performance of $\mathrm{Li}-\mathrm{O}_{2}$ battery in the presence of trapper- $\mathrm{LiO}_{2}$ complex}

The above results showed that DFAQ trapper had the advantages of promoting surface-mediated ORR and high electrochemical stability. Therefore, it was introduced as additives in the LiTFSI/TEGDME electrolyte to improve the performance of $\mathrm{Li}-\mathrm{O}_{2}$ batteries. The self-supporting CP@CNTs (the preparation method of CP@CNT electrode and its morphology is shown in Fig. S6) and metallic lithium were used as the $\mathrm{O}_{2}$ cathode and anode, respectively. A PSS-Li/GO-Li/GF membrane separator was used to alleviate the diffusion of redox chemicals from cathode to anode (the surface morphology of PSSLi/GO-Li/GF separator is shown in Fig. S7, and the inhibited diffusion of redox chemicals by PSS-Li/GO-Li/GF separator can be found in Fig. S8). Fig. 5a-d and Fig. S9 show that batteries without additive and with $10 \mathrm{~mol} \mathrm{~L}^{-1}$ AQ, TBAQ, DFAQ, DBBQ molecules could deliver 5.2, $7.0,7.5,13.5$ and $6.5 \mathrm{~mA} \mathrm{~h} \mathrm{~cm}^{-2}$, respectively, at a current density of $100 \mu \mathrm{A} \mathrm{cm}^{-2}$. When the current density was increased to $500 \mu \mathrm{A} \mathrm{cm}{ }^{-2}$, the corresponding capacities decreased to $2.3,4.5,5.5,10.6$, and $2.7 \mathrm{~mA} \mathrm{~h} \mathrm{~cm}^{-2}$, respectively. The results clearly showed that DFAQ could provide the maximum improvements of battery capacities from 5.2 to $13.5 \mathrm{~mA} \mathrm{~h} \mathrm{~cm}^{-2}$ and 2.3 to $10.6 \mathrm{~mA} \mathrm{~h} \mathrm{~cm}^{-2}$, respectively, at different current densities compared with those of the blank references. Fig. 5a also shows that the batteries with DFAQ had the lowest capacity fade rate of $22 \%$, indicating its excellent rate capability. Compared with previously reported $A Q$, the capacities of the battery with DFAQ increased to about 2.0 times at $100 \mu \mathrm{A} \mathrm{cm}$ $\left(7.0 \rightarrow 13.5 \mathrm{~mA} \mathrm{~h} \mathrm{~cm}^{-2}\right)$ and 2.4 times at $500 \mu \mathrm{A} \mathrm{cm}$ $\left(4.5 \rightarrow 10.6 \mathrm{~mA} \mathrm{~h} \mathrm{~cm}^{-2}\right)$. The enhanced capacity could be attributed to the higher surface-mediated ORR activity in the presence of DFAQ than that of AQ. To confirm the role of these additives on the cell capacities, the mor- 

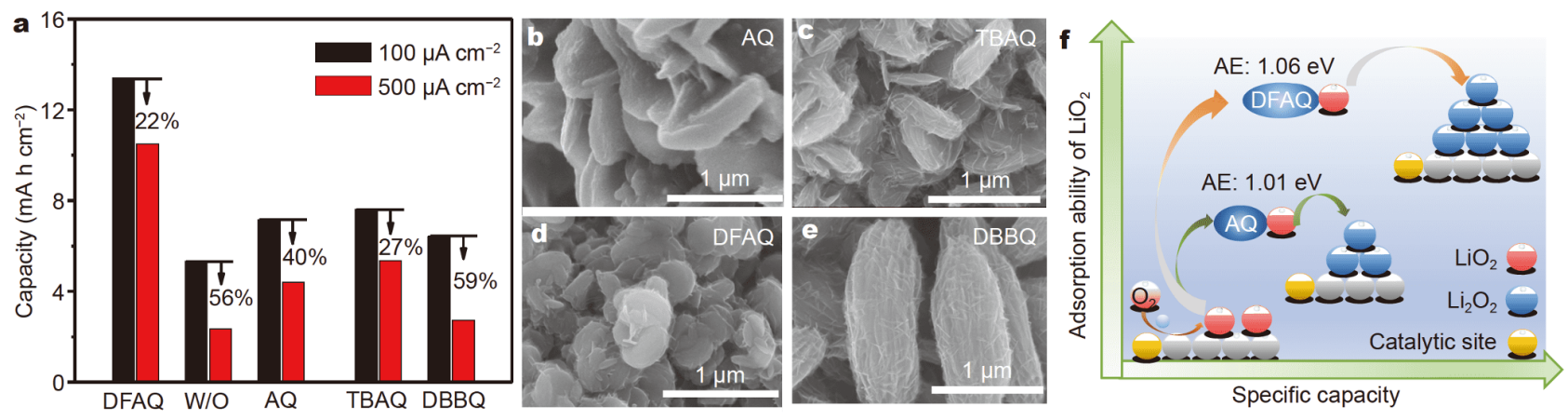

Figure 5 (a) Cell discharge capacities with the additives at different current densities. SEM images of the discharged products with (b) AQ, (c) TBAQ, (d) DFAQ and (e) DBBQ at a capacity of $2 \mathrm{~mA} \mathrm{~h} \mathrm{~cm}$. (f) Schematic diagram for the role of $\mathrm{LiO}_{2}$ adsorption energy on battery capacity.

phology of discharge products was observed by SEM (Fig. 5b-e). The discharge products without AQ derivatives exhibited a typical toroid structure with a diameter of about $500 \mathrm{~nm}$ (Fig. S10). For DFAQ (Fig. 5d), the diameter and thickness of the discharge products increased when compared with those without additives, like the condition of AQ and TBAQ (Fig. $5 b$ and $c$ ). The discharge products in the presence of DBBQ were of a larger size compared with those obtained using AQ derivatives. The different morphologies of the discharge products with different quinones can be attributed to different ORR mechanisms, of which the enhanced surface-mediated and solution-mediated ORR activities evolved in the presence of AQ derivatives and DBBQ, respectively.

As shown in Fig. 5f, the higher $\mathrm{AE}$ of $\mathrm{LiO}_{2}$ can assist the transfer of $\mathrm{LiO}_{2}$ from the electrode surface into the electrolyte more efficiently, avoiding the formation of film-like $\mathrm{Li}_{2} \mathrm{O}_{2}$ and further ensuring the availability of surface-active sites. Under these conditions, surfacemediated ORR can occur efficiently on the cathode surface. As discussed above, the high $\mathrm{AE}$ of $\mathrm{LiO}_{2}$ can efficiently regenerate surface-active sites to maintain the duration of high ORR rates. Shortly after, the high cell capacity and rate capability are realized. It is interesting to note that the capacity of the battery with DBBQ reduced by $59 \%$ when the current was increased from 100 to $500 \mu \mathrm{A} \mathrm{cm}^{-2}$ (Fig. 5a). There were two reasons that could explain this result. Firstly, solution-mediated ORR with DBBQ had a different discharge mechanism compared with surface-mediated $\mathrm{ORR}$ with the $\mathrm{AQ}$ derivative [22,36-38]. DBBQ was initially reduced to $\mathrm{DBBQ}^{-} \mathrm{Li}^{+}$in the electrolyte and then oxidized by $\mathrm{O}_{2}$ to form DBBQ$\mathrm{LiO}_{2}$, which further transferred back to DBBQ after disproportionation (2DBBQ- $\mathrm{LiO}_{2} \rightarrow \mathrm{Li}_{2} \mathrm{O}_{2}+2 \mathrm{DBBQ}+\mathrm{O}_{2}$ ) or reduction (DBBQ- $\left.\mathrm{LiO}_{2}+\mathrm{Li}^{+}+\mathrm{e}^{-} \rightarrow \mathrm{DBBQ}+\mathrm{Li}_{2} \mathrm{O}_{2}\right)$. The rate of solution-mediated ORR based on an indirect electron transfer pathway was much lower than the surfacemediated ORR pathway based on a direct electron transfer pathway. Secondly, DFAQ possessed a higher DC than DBBQ $\left(1.53 \times 10^{-6}\right.$ vs. $\left.6.28 \times 10^{-7} \mathrm{~cm}^{2} \mathrm{~s}^{-1}\right)$. The solution growth of $\mathrm{Li}_{2} \mathrm{O}_{2}$ via the assistance of DFAQ was much faster than that via DBBQ. The acceleration of surface-mediated ORR by $\mathrm{LiO}_{2}$ trapper is of great significance to solve the problems of electron transfer constraints and deactivation of active sites caused by the filmlike and insulating $\mathrm{Li}_{2} \mathrm{O}_{2}$. This finding will help to overcome the low capacity and rate capability limitations of $\mathrm{Li}-\mathrm{O}_{2}$ batteries.

The increased stability of $\mathrm{LiO}_{2}$ intermediate without and with trappers not only affects the capacity and rate capability of $\mathrm{Li}-\mathrm{O}_{2}$ batteries, but also influences their cycle stability due to the reduced oxidation activity of $\mathrm{LiO}_{2}$ in the bound state (anthraquinones- $\mathrm{LiO}_{2}$ ). To confirm this point, the cyclic tests of assembled $\mathrm{Li}-\mathrm{O}_{2}$ batteries were conducted at a fixed capacity of $0.5 \mathrm{~mA} \mathrm{~h} \mathrm{~cm}^{-2}$ at $100 \mu \mathrm{A} \mathrm{cm}^{-2}$. As shown in Fig. S11, the batteries without additive and with DBBQ, AQ, TBAQ, DFAQ were maintained over 20, 29, 32, 28 and 53 cycles, respectively.

As previously reported, the cathode surface was usually passivated during battery cycling. This was due to the accumulation of byproducts caused by the electro-oxidation of electrolyte/electrode at high charging potentials, and the chemical reaction between electrolyte/electrode and radical species, such as $\mathrm{MO}_{2}$ and the singlet $\mathrm{O}_{2}\left({ }^{1} \mathrm{O}_{2}\right)$ which was also detected during battery operation, especially at high charging potentials [39-43]. To evaluate the critical role of quinones during battery operation more accurately, the side reaction originating from high charging potentials and ${ }^{1} \mathrm{O}_{2}$ species should be reduced as much as possible. Consequently, the introduction of oxygen evolution reaction (OER) redox mediators was 
considered as an efficient method to reduce charging potentials, and 2,2,6,6-tetramethylpiperidine- $N$-oxyl $[44,45]$ was simultaneously added into the electrolyte. As expected, and DFAQ-assisted $\mathrm{Li}^{-\mathrm{O}_{2}}$ battery also performed the best (Fig. 6b). The battery cycle life with DFAQ was 2.6 times compared with those with AQ (105 $v s .40$ cycles) and 4.0 times compared with those without additives (105 vs. 26 cycles) (Fig. 6a).

In order to clarify the reason for the effect of the $\mathrm{LiO}_{2}$ bound state on cell cyclic stability, the composition of product on the cathode was characterized with different techniques. XRD patterns showed two peaks at about $33^{\circ}$ and $35^{\circ}$ assigned to crystalline $\mathrm{Li}_{2} \mathrm{O}_{2}$ (Fig. 6c) $[46,47]$. The Raman spectra showed the peaks at 250 and $790 \mathrm{~cm}^{-1}$ corresponding to $\mathrm{Li}_{2} \mathrm{O}_{2}$. When $\mathrm{AQ}, \mathrm{TBAQ}$ and $\mathrm{DBBQ}$ were added, peaks corresponding to $\mathrm{C}-\mathrm{O}$ bond appeared at $\sim 1100 \mathrm{~cm}^{-1}$, indicating the existence of $\mathrm{Li}_{2} \mathrm{CO}_{3}$ in these cases (Fig. 6d) $[46,48,49]$. The peak at $1100 \mathrm{~cm}^{-1}$ was not observed for DFAQ, consistent with the effect of DFAQ$\mathrm{LiO}_{2}$ complex on the stability of the electrolyte and batteries. Specifically, DFAQ could effectively bind and stabilize the $\mathrm{LiO}_{2}$ intermediate, avoiding the formation of byproducts caused by $\mathrm{LiO}_{2}$ (Fig. 6e). Infrared (IR) spectra further confirmed that $\mathrm{Li}_{2} \mathrm{O}_{2}$ was the primary discharge product (Fig. S12).

Based on the above findings, we investigated the influence of trapper concentration on ORR activity and the performance of $\mathrm{Li}-\mathrm{O}_{2}$ batteries (Figs S13-S15). The cell capacities and cyclic stability of the $\mathrm{Li}-\mathrm{O}_{2}$ batteries reach the maximum value of $16.8 \mathrm{~mA} \mathrm{~h} \mathrm{~cm}^{-2}$, and 170 cycles with $30 \mathrm{mmol} \mathrm{L}^{-1}$ DFAQ at a fixed capacity of $0.5 \mathrm{~mA} \mathrm{~h} \mathrm{~cm}^{-2}$ at $100 \mu \mathrm{A} \mathrm{cm}^{-2}$. The SEM, XRD, Raman and IR results confirmed that $\mathrm{Li}_{2} \mathrm{O}_{2}$ was the only product (Figs S16 and S17). These results demonstrated the most improved cooperative ORR catalysis in $\mathrm{M}-\mathrm{O}_{2}$ batteries reported so far.

\section{CONCLUSIONS}

To date, the attainment of high activity and stability in ORR involving $1 \mathrm{e}^{-}$and $2 \mathrm{e}^{-}$pathways in aprotic media has been impeded by the low stability of $\mathrm{MO}_{2}$ intermediate, which severely limits the discharge capacity, rate performance and cycle life of $\mathrm{M}-\mathrm{O}_{2}$ batteries. In this study, an aprotic $\mathrm{Li}-\mathrm{O}_{2}$ system, representing a $2 \mathrm{e}^{-}$ORR model, was used to modulate the stability of $\mathrm{MO}_{2}$ by introducing $\mathrm{AQ}$ derivatives as the cocatalyst. Among the studied molecules, DFAQ with electron-withdrawing substituents had the highest $\mathrm{LiO}_{2} \mathrm{AE}$ and formed the most stable complex with $\mathrm{LiO}_{2}$, i.e., DFAQ- $\mathrm{LiO}_{2}$. This greatly improved the surface-mediated ORR rate and reduced the side reactions related to $\mathrm{LiO}_{2}$. Compared with the batteries without $\mathrm{LiO}_{2}$ trapper, the capacity, cycle life and rate performance of $\mathrm{Li}^{-\mathrm{O}_{2}}$ batteries with DFAQ were increased by 4,5 and 3 times, respectively. These findings surpassed the reported performance of DBBQ catalyst and AQ trapper, which had, so far, exhibited the highest capability in enhancing cathodic ORR. This study provides an important understanding of the mechanism of
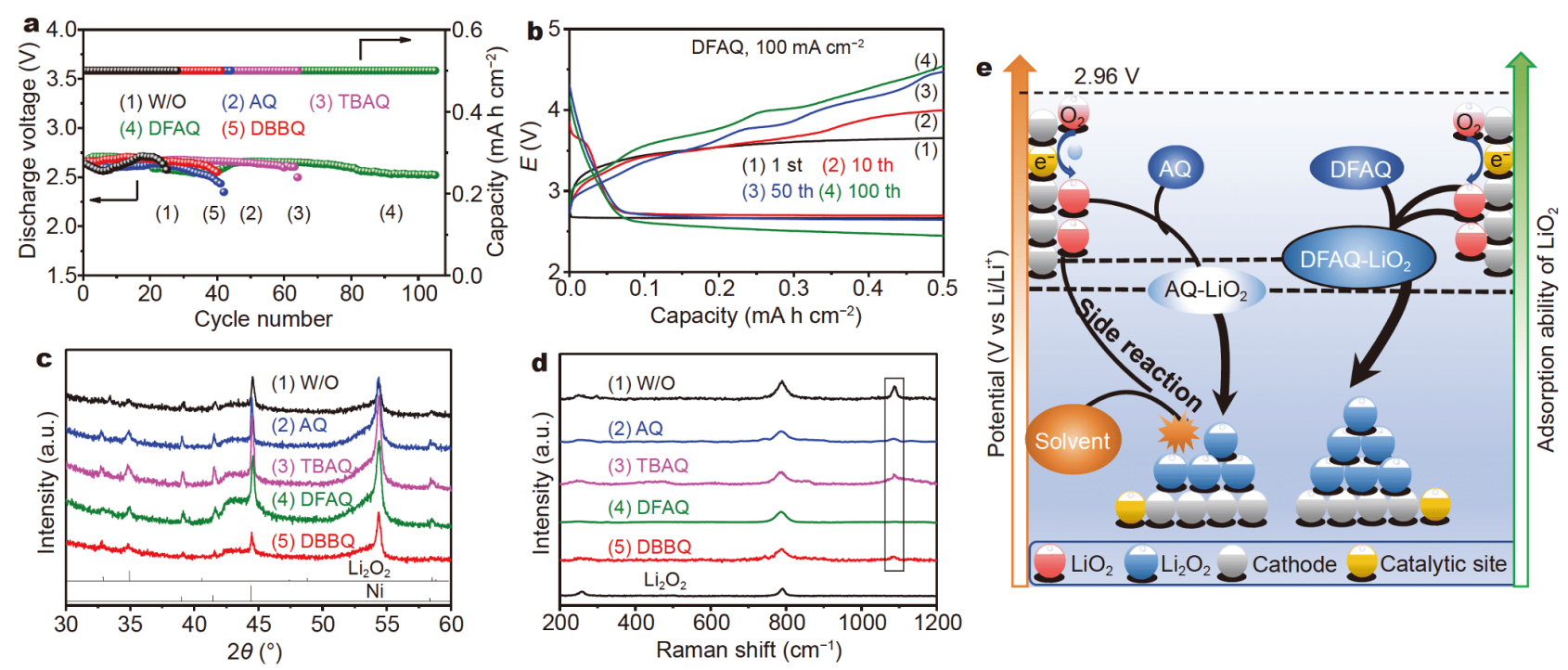

Figure 6 (a) Comparison of cell cyclic stability of the battery without quinone (black), with DBBQ (red), with AQ (blue), with TBAQ (pink), and with DFAQ (green) in the presence of 2,2,6,6-tetramethylpiperidine- $N$-oxyl (TEMPO). (b) Charge/discharge profiles of battery with DFAQ and TEMPO. (c) XRD and (d) Raman spectra of the discharged electrodes with additives. The dashed rectangle in (d) indicated the byproducts. (e) Schematic diagram for the influence of $\mathrm{LiO}_{2}$ adsorption energy on side reaction induced by $\mathrm{LiO}_{2}$. 
surface-mediated ORR and its application in $\mathrm{M}-\mathrm{O}_{2}$ batteries. It should also provide a valuable guide for improving the performance of other energy storage devices and the catalytic reactions with similar mechanisms.

\section{Received 28 April 2020; accepted 14 September 2020;} published online 15 December 2020

1 Liu T, Vivek JP, Zhao EW, et al. Current challenges and routes forward for nonaqueous lithium-Air batteries. Chem Rev, 2020, 120: 6558-6625

2 He X, Liu X, Han Q, et al. A liquid/liquid electrolyte interface that inhibits corrosion and dendrite growth of lithium in lithium-metal batteries. Angew Chem Int Ed, 2020, 59: 6397-6405

3 Kwak WJ, Rosy WJ, Sharon D, et al. Lithium-oxygen batteries and related systems: potential, status, and future. Chem Rev, 2020, 120: 6626-6683

4 Sheng C, Yu F, Wu Y, et al. Disproportionation of sodium superoxide in metal-air batteries. Angew Chem Int Ed, 2018, 57: 9906-9910

5 Kim J, Park H, Lee B, et al. Dissolution and ionization of sodium superoxide in sodium-oxygen batteries. Nat Commun, 2016, 7: 10670

6 Zhang X, Guo L, Gan L, et al. $\mathrm{LiO}_{2}$ : Cryosynthesis and chemical/ electrochemical reactivities. J Phys Chem Lett, 2017, 8: 2334-2338

7 Zhao S, Qin B, Chan K, et al. Recent development of aprotic Na $-\mathrm{O}_{2}$ batteries. Batteries Supercaps, 2019, 2: 725-742

8 Li F, Chen J. Mechanistic evolution of aprotic lithium-oxygen batteries. Adv Energy Mater, 2017, 7: 1602934

9 Cheng F, Chen J. Metal-air batteries: from oxygen reduction electrochemistry to cathode catalysts. Chem Soc Rev, 2012, 41: 2172-2192

10 Zhang $\mathrm{P}$, Zhao $\mathrm{Y}$, Zhang X. Functional and stability orientation synthesis of materials and structures in aprotic $\mathrm{Li}-\mathrm{O}_{2}$ batteries. Chem Soc Rev, 2018, 47: 2921-3004

11 Yu M, Zhou S, Liu Y, et al. Long life rechargeable $\mathrm{Li}^{-} \mathrm{O}_{2}$ batteries enabled by enhanced charge transfer in nanocable-like Fe@N-doped carbon nanotube catalyst. Sci China Mater, 2017, 60: 415-426

12 Xia C, Fernandes R, Cho FH, et al. Direct evidence of solutionmediated superoxide transport and organic radical formation in sodium-oxygen batteries. J Am Chem Soc, 2016, 138: 11219-11226

13 Yadegari H, Sun Q, Sun X. Sodium-oxygen batteries: A comparative review from chemical and electrochemical fundamentals to future perspective. Adv Mater, 2016, 28: 7065-7093

14 Lyu Z, Zhou Y, Dai W, et al. Recent advances in understanding of the mechanism and control of $\mathrm{Li}_{2} \mathrm{O}_{2}$ formation in aprotic $\mathrm{Li}-\mathrm{O}_{2}$ batteries. Chem Soc Rev, 2017, 46: 6046-6072

15 Xiao L, Yi J, Meng W, et al. Ball-flower-like carbon microspheres via a three-dimensional replication strategy as a high-capacity cathode in lithium-oxygen batteries. Sci China Mater, 2019, 62: 633-644

16 Radin MD, Siegel DJ. Charge transport in lithium peroxide: Relevance for rechargeable metal-air batteries. Energy Environ Sci, 2013, 6: 2370-2379

17 Liu X, Zhang P, Liu L, et al. Inhibition of discharge side reactions by promoting solution-mediated oxygen reduction reaction with stable quinone in $\mathrm{Li}-\mathrm{O}_{2}$ batteries. ACS Appl Mater Interfaces, 2020, 12: 10607-10615

18 Black R, Oh SH, Lee JH, et al. Screening for superoxide reactivity in $\mathrm{Li}-\mathrm{O}_{2}$ batteries: Effect on $\mathrm{Li}_{2} \mathrm{O}_{2} / \mathrm{LiOH}$ crystallization. $\mathrm{J}$ Am
Chem Soc, 2012, 134: 2902-2905

19 Lim HD, Lee B, Bae Y, et al. Reaction chemistry in rechargeable $\mathrm{Li}-\mathrm{O}_{2}$ batteries. Chem Soc Rev, 2017, 46: 2873-2888

20 Black R, Shyamsunder A, Adeli P, et al. The nature and impact of side reactions in glyme-based sodium-oxygen batteries. ChemSusChem, 2016, 9: 1795-1803

21 Frith JT, Landa-Medrano I, de Larramendi IR, et al. Improving $\mathrm{Na}-\mathrm{O}_{2}$ batteries with redox mediators. Chem Commun, 2017, 53: 12008-12011

22 Gao X, Chen Y, Johnson L, et al. Promoting solution phase discharge in $\mathrm{Li}-\mathrm{O}_{2}$ batteries containing weakly solvating electrolyte solutions. Nat Mater, 2016, 15: 882-888

23 Zhang Y, Wang L, Zhang X, et al. High-capacity and high-rate discharging of a coenzyme $\mathrm{Q}_{10}$-catalyzed Li- $\mathrm{O}_{2}$ battery. Adv Mater, 2017, 30: 1705571

24 Ko Y, Park H, Kim J, et al. Biological redox mediation in electron transport chain of bacteria for oxygen reduction reaction catalysts in lithium-oxygen batteries. Adv Funct Mater, 2019, 29: 1805623

25 Wasylenko DJ, Rodríguez C, Pegis ML, et al. Direct comparison of electrochemical and spectrochemical kinetics for catalytic oxygen reduction. J Am Chem Soc, 2014, 136: 12544-12547

26 Pegis ML, McKeown BA, Kumar N, et al. Homogenous electrocatalytic oxygen reduction rates correlate with reaction overpotential in acidic organic solutions. ACS Cent Sci, 2016, 2: 850-856

$27 \mathrm{Xu} \mathrm{C}, \mathrm{Xu} \mathrm{G}$, Zhang Y, et al. Bifunctional redox mediator supported by an anionic surfactant for long-cycle $\mathrm{Li}-\mathrm{O}_{2}$ batteries. ACS Energy Lett, 2017, 2: 2659-2666

28 Pande V, Viswanathan V. Criteria and considerations for the selection of redox mediators in nonaqueous $\mathrm{Li}-\mathrm{O}_{2}$ batteries. ACS Energy Lett, 2017, 2: 60-63

29 Zhang P, Liu L, He X, et al. Promoting surface-mediated oxygen reduction reaction of solid catalysts in metal- $\mathrm{O}_{2}$ batteries by capturing superoxide species. J Am Chem Soc, 2019, 141: 6263-6270

30 Liang D, Bian T, Han Q, et al. Inhibiting the shuttle effect using artificial membranes with high lithium-ion content for enhancing the stability of the lithium anode. J Mater Chem A, 2020, 8: 1406214070

31 Peng Z, Chen Y, Bruce PG, et al. Direct detection of the superoxide anion as a stable intermediate in the electroreduction of oxygen in a non-aqueous electrolyte containing phenol as a proton source. Angew Chem Int Ed, 2015, 54: 8165-8168

32 Bryantsev VS, Giordani V, Walker W, et al. Predicting solvent stability in aprotic electrolyte li-air batteries: nucleophilic substitution by the superoxide anion radical $\left(\mathrm{O}_{2}{ }^{--}\right)$. J Phys Chem A, 2011, 115: 12399-12409

33 Laoire CO, Mukerjee S, Abraham KM, et al. Influence of nonaqueous solvents on the electrochemistry of oxygen in the rechargeable lithium-air battery. J Phys Chem C, 2010, 114: 91789186

34 McCloskey BD, Scheffler R, Speidel A, et al. On the mechanism of nonaqueous $\mathrm{Li}-\mathrm{O}_{2}$ electrochemistry on $\mathrm{C}$ and its kinetic overpotentials: Some implications for $\mathrm{Li}$-air batteries. J Phys Chem C, 2012, 116: 23897-23905

35 Zhai D, Lau KC, Wang $\mathrm{HH}$, et al. Interfacial effects on lithium superoxide disproportionation in $\mathrm{Li}^{-} \mathrm{O}_{2}$ batteries. Nano Lett, 2015, 15: $1041-1046$

36 Liu T, Frith JT, Kim G, et al. The effect of water on quinone redox mediators in nonaqueous $\mathrm{Li}^{-} \mathrm{O}_{2}$ batteries. J Am Chem Soc, 2018, 140: $1428-1437$

37 Huang W, Zhang X, Zheng S, et al. Calix[6]quinone as high-per- 
formance cathode for lithium-ion battery. Sci China Mater, 2020, 63: $339-346$

38 Shen ZZ, Lang SY, Shi Y, et al. Revealing the surface effect of the soluble catalyst on oxygen reduction/evolution in $\mathrm{Li}-\mathrm{O}_{2}$ batteries. J Am Chem Soc, 2019, 141: 6900-6905

39 Schwager P, Dongmo S, Fenske D, et al. Reactive oxygen species formed in organic lithium-oxygen batteries. Phys Chem Chem Phys, 2016, 18: 10774-10780

40 McCloskey BD, Bethune DS, Shelby RM, et al. Solvents' critical role in nonaqueous lithium-oxygen battery electrochemistry. J Phys Chem Lett, 2011, 2: 1161-1166

41 Wandt J, Jakes P, Granwehr J, et al. Singlet oxygen formation during the charging process of an aprotic lithium-oxygen battery. Angew Chem Int Ed, 2016, 55: 6892-6895

42 Mahne N, Schafzahl B, Leypold C, et al. Singlet oxygen generation as a major cause for parasitic reactions during cycling of aprotic lithium-oxygen batteries. Nat Energy, 2017, 2: 17036

43 Mourad E, Petit YK, Spezia R, et al. Singlet oxygen from cation driven superoxide disproportionation and consequences for aprotic metal- $\mathrm{O}_{2}$ batteries. Energy Environ Sci, 2019, 12: 2559-2568

44 Bergner BJ, Schürmann A, Peppler $\mathrm{K}$, et al. TEMPO: A mobile catalyst for rechargeable $\mathrm{Li}_{-} \mathrm{O}_{2}$ batteries. J Am Chem Soc, 2014, 136: 15054-15064

45 Chen Y, Gao X, Johnson LR, et al. Kinetics of lithium peroxide oxidation by redox mediators and consequences for the lithiumoxygen cell. Nat Commun, 2018, 9: 767

$46 \mathrm{Hu} \mathrm{Y}$, Zhang T, Cheng F, et al. Recycling application of $\mathrm{Li}^{-\mathrm{MnO}_{2}}$ batteries as rechargeable lithium-air batteries. Angew Chem Int Ed, 2015, 54: 4338-4343

47 Zhang $\mathrm{P}$, Wang R, He $\mathrm{M}$, et al. 3D hierarchical Co/CoO-graphenecarbonized melamine foam as a superior cathode toward long-life lithium oxygen batteries. Adv Funct Mater, 2016, 26: 1354-1364

48 Gittleson FS, Yao KPC, Kwabi DG, et al. Raman spectroscopy in lithium-oxygen battery systems. ChemElectroChem, 2015, 2: 1446-1457

49 Wang J, Zhang Y, Guo L, et al. Identifying reactive sites and transport limitations of oxygen reactions in aprotic lithium- $\mathrm{O}_{2}$ batteries at the stage of sudden death. Angew Chem Int Ed, 2016, 55: 5201-5205

Acknowledgements This work was supported by the National Natural Science Foundation of China (21773055, U1604122, 51702086, 21203055 and 21805070), the Program for Science \& Technology Innovation Talents in Universities of Henan Province (18HASTIT004), and China Postdoctoral Science Foundation (2020M672201).

Author contributions Wang $\mathrm{H}$ and Liu X performed the experiments; Liu L and Jia Y contributed to the theoretical analysis; Zhao Y and Zhang $\mathrm{P}$ proposed the research direction, analyzed the data and wrote the manuscript. All authors contributed to the general discussion.

Conflict of interest The authors declare that they have no conflict of interest.

Supplementary information Supplementary materials to this article can be found online.

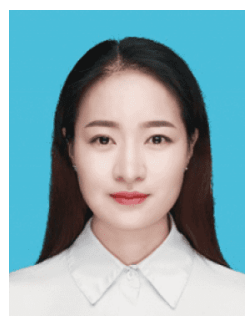

Hua Wang received her bachelor's degree from the School of Chemistry and Chemical Engineering of Anyang Normal University in 2017, and master's degree from Henan University in 2020. Her research focuses on the functional electrolytes of metal-oxygen batteries.

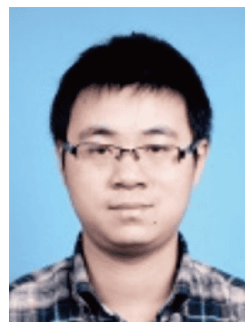

Liangliang Liu received his $\mathrm{PhD}$ degree in condensed matter physics from Wuhan University in 2015. During 2017-2018, he was a visiting postdoctoral researcher at Hanyang University in South Korea. He is currently an assistant professor at Henan University. His research focuses on the design of electrolytes for metal-oxygen batteries.

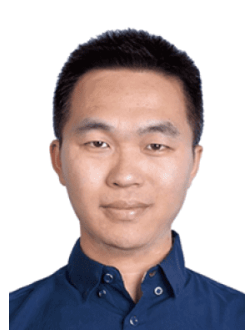

Peng Zhang received his $\mathrm{PhD}$ from Lanzhou Institute of Chemical Physics, Chinese Academy of Sciences, in 2016 under the supervision of Professor Xingbin Yan. During 2017-2018, he worked at the Key Laboratory for Special Functional Materials of the Ministry of Education, Henan University. He is currently undertaking post-doctoral research at the Southern University of Science and Technology. His research interests focus on the electrochemical interface reaction of lithium-based batteries.

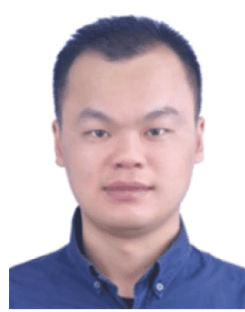

Yong Zhao received his $\mathrm{PhD}$ from the Institute of Chemistry, Chinese Academy of Sciences, in 2008 under the supervision of Professor Lei Jiang. After a period working as a postdoctoral fellow with Professor Kazuhito Hashimoto at the University of Tokyo (2008-2015), he became a full professor at Henan University in 2016. His research interests focus on the mechanism of electrocatalytic reactions and electrolyte innovation in lithium-metal batteries.

\section{金属-氧气电池中调控超氧化物稳定性实现大幅 增强的固体催化剂氧还原反应活性}

$$
\text { 王华 }{ }^{1 \dagger} \text {, 刘亮亮 }{ }^{1 \dagger} \text {, 刘肖 }{ }^{1} \text {, 贾瑜 }{ }^{1} \text {, 张鹏 }{ }^{2,3^{*}} \text {, 赵勇 }{ }^{1^{*}}
$$

摘要 单电子或双电子氧还原反应 $(\mathrm{ORR})$ 是非质子型金属-氧气电池 的关键过程, 其中超氧化物中间体或产物 $\left(\mathrm{O}_{2}{ }^{-}, \mathrm{LiO}_{2}, \mathrm{NaO}_{2}\right.$ 等)的稳定 性决定了催化剂的ORR活性/稳定性和电池的整体性能. 然而, 超氧化 物具有高反应活性的特点导致其稳定性难以调控. 本文将葸醌衍生物 作为助催化剂, 成功实现了超氧化物稳定性的调控. 在ORR过程中, 该 助催化剂首先吸附固体催化剂表面生成的超氧化物, 并将其转移至电 解液中. 研究发现, 含吸电子基团的 1,4-二氟葱醌(DFAQ)对超氧化物 的吸附强度最高, 能最大程度地将 $\mathrm{LiO}_{2}$ 稳定在电解液中, 从而大幅提 高了表面ORR的反应速率和稳定性. 这一结果证明助催化剂对 $\mathrm{LiO}_{2}$ 吸 附能的强弱对ORR的活性/稳定性具有重要影响. 以锂氧电池作为金 属-氧气电池的模型器件, 发现DFAQ分子的引入能够显著提高电池 的容量、倍率性能和循环稳定性. 本工作有助于深入理解ORR反应 机制和提高金属-氧气电池的电化学性能. 